Vol. 3, No. 2, June 2021 e-ISSN: 2656-4882 p-ISSN: 2656-5935

\title{
Perencanaan Strategis Sistem Informasi Di Sinode GKJ Menggunakan Enterprise Architecture Planning Framework
}

\author{
Monika Prianti ${ }^{1}$, Frederik Samuel Papilaya ${ }^{2}$ \\ ${ }^{1}$ Sistem Informasi, Universitas Kristen Satya Wacana, Salatiga, Indonesia. \\ Email: 1682017408@student.uksw.edu ,2samuel.papilaya@uksw.edu
}

\begin{abstract}
Abstrak
Sinode GKJ Salatiga saat ini sudah memiliki sistem akan tetapi masih memiliki kendala yang terdapat pada masalah Sistem Informasi yang belum diterapkan secara optimal, sehingga sering kali terdapat hambatan ketika melakukan pekerjaan. Karena tidak berjalan dengan cepat dan baik, maka dari itu dibutuhkan suatu Perencanaan Strategis Sistem Informasi, Tujuan dari penelitian ini adalah untuk mengusulkan dan merencanakan sistem informasi menggunakan metode Enterprise Architecture Planning. Enterprise Architecture Planning (EAP) merupakan proses pendefinisian arsitektur dalam penggunaan sistem informasi untuk mendukung rencana implementasi arsitektur. Dengan menggunakan pendekatan Enterprise Architecture Planning (EAP) metode dapat membantu sinode GKJ Salatiga perencanaan kualitas data yang berorientasi untuk kebutuhan organisasi agar dapat mencapai dan mendukung sasaran organisasi, selain itu juga keuntungan menggunakan Enterprise Architecture Planning merupakan metode pendukung untuk mengambil keputusan dan perencanaan yang baik untuk sebuah organisasi. Portofolio solusi sistem informasi disusun berdasarkan kajian dan analisis yang sudah dilakukan terdapat aktivitas utama dan aktivitas pendukung yang diidentifikasi menggunakan value chain activity dan menggunakan analisis SWOT untuk mengevaluasi kekuatan (strengths), kelemahan (weaknesses), peluang (opportunities), dan ancaman (threats).
\end{abstract}

Kata kunci: Enterprise Architecture planning (EAP) framework, Perencanaan strategis, sistem informasi, Sinode GKJ

\section{PENDAHULUAN}

Sebuah organisasi terdapat sistem informasi yang harus berjalan dengan baik dikarenakan untuk kepentingan suatu peningkatan proses bisnis yang sedang dijalankan oleh organisasi. Sistem informasi tersebut merupakan sebuah sistem yang sangat berpengaruh pada komponen-komponen pengelolaan data menjadi sebuah informasi yang penting pada organisasi[1]. Sistem informasi bukan sekedar support melainkan sekarang sudah menjadi kebutuhan operasional yang berkaitan penting dengan sebuah organisasi saat ini. Penggunaan sistem informasi dan 
Vol. 3, No. 2, June 2021

p-ISSN: 2656-5935 http://journal-isi.org/index.php/isi e-ISSN: 2656-4882

teknologi informasi dalam proses bisnis sangat dibutuhkan untuk kebutuhan untuk meningkatkan proses bisnis [2].

Enterprise Architecture planning (EAP) adalah suatu metode yang dapat digunakan untuk membangun suatu informasi yang berkaitan dengan arsitektur enterprise dimana pendekatan sebuah perencanaan kualitas data dapat berorientasi untuk kebutuhan organisasi, serta cara implementasi dari arsitektur yang dilakukan berupa usaha dalam mendukung dan mencapai sebuah perputaran roda bisnis dan sistem informasi di organisasi[3]. Enterprise Architecture Planning (EAP) merupakan suatu metodologi yang digunakan untuk merencanakan arsitektur enterprise yang memfokuskan pada arsitektur data, arsitektur aplikasi serta arsitektur teknologi yang berorientasi pada kebutuhan bisnis serta bagaimana cara implementasi arsitektur yang dibuat sehingga dapat mendukung pencapaian tujuan organisasi. Enterprise Architecture Planning adalah proses pendefinisian arsitektur dalam penggunaan informasi untuk mendukung bisnis dan rencana untuk mengimplementasikan arsitektur tersebut (Spewak, 1992), Pada dasarnya Enterprise Architecture Planning (EAP) bukan merancang bisnis dan arsitekturnya, tetapi mendefinisikan kebutuhan bisnis dan arsitekturnya[4]. Enterprise architecture planning merupakan pengarahan dalam perencanaan yang didukung berdasarkan kebutuhan aktivitas sampai ke tahap uji coba sebuah perencanaan penataan sebuah desain untuk membantu sasaran yang ingin dicapai sistem informasi proses bisnis yang ingin dicapai [5].

Sinode GKJ Salatiga merupakan salah satu Yayasan Gereja yang terdapat di Jawa Tengah khususnya kota Salatiga, Pada bagian pusat data informasi dan layanan media Sinode GKJ. Terdapat masalah dari hasil wawancara yang telah dilaksanakan bahwa Sistem Informasi yang telah ada di Sinode GKJ Salatiga belum diterapkan secara optimal, sehingga sering kali terdapat hambatan Ketika melakukan pekerjaan. Karena tidak berjalan dengan cepat dan baik, maka dari itu penelitian kali ini bertujuan untuk dapat membantu proses kinerja dengan mengusulkan Perencanaan strategis menggunakan metode Enterprise Architecture Planning (EAP) agar untuk mengoptimalkan sebuah sistem yang sudah ada dan dapat digunakan dengan baik oleh kinerja. Perencanaan Enterprise Architecture Planning (EAP) diusulkan untuk mengenalkan fungsi dari Sistem Informasi yang sangat diperlukan pada era globalisasi seperti sekarang ini,untuk dapat membantu sebuah instansi maupun organisasi dapat bersaing secara pesat.

\section{METODOLOGI PENELITIAN}

Berikut merupakan gambar 2 Flowchart Metodologi Penelitian pada Perencanaan Strategis Sistem Informasi Di Sinode GKJ Menggunakan Enterprise Architecture Planning Framework: 
Vol. 3, No. 2, June 2021

p-ISSN: 2656-5935 http://journal-isi.org/index.php/isi e-ISSN: 2656-4882

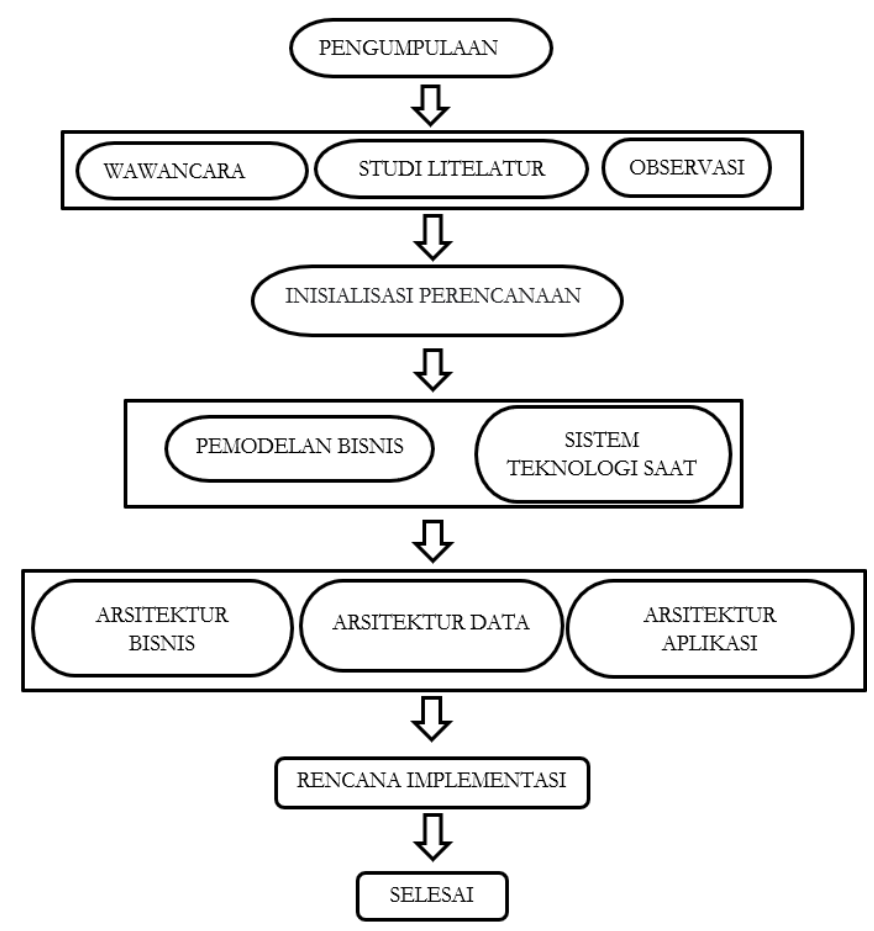

Gambar 2 Flowchart Metodologi Penelitian

Tahap penelitian yang digunakan untuk pengumpulan data ini adalah dengan melakukan wawancara,studi literatur,dan observasi. Wawancara dengan narasumber untuk mendapatkan data terkait penelitian yang diambil untuk mengumpulkan data yang diperlukan. Wawancara yang dilakukan untuk pengumpulan data dilakukan dengan tanya jawab Bersama dengan staff pada bagian pusat data informasi dan layanan media Sinode GKJ. Studi Literatur adalah penelitian yang menggunakan Pustaka atau melihat penelitian sebelumnya. Studi Literatur dapat dilakukan dengan membaca,mencatat,dan mencari di internet atau jurnal tentang Pustaka studi kasus yang sedang diteliti. Studi Literatur juga sebuah informasi atau referensi untuk memperluas sebuah pengetahuan tentang penelitian yang sekarang sendang dibuat atau diteliti. Observasi merupakan pengumpulan data dengan mengamati dan datang langsung ke lokasi untuk mengamati kondisi perusahaan atau organisasi yang sedang diteliti. Inisialisasi Perencanaan adalah menganalisa bagaimana sebuah perusahaan atau organisasi pemodelan bisnis yang saat ini digunakan. Arsitektur bisnis, arsitektur data dan arsitektur aplikasi bagaimana penerapannya di organisasi tersebut. Rencana Implementasi ini bertujuan untuk menyusun dan menyiapkan suatu rekomendasi pengimplementasian dengan menentukan kebijakan, standar, prosedur-prosedur dan yang sudah direncanakan secara terperinci. 
Vol. 3, No. 2, June 2021

p-ISSN: 2656-5935 http://journal-isi.org/index.php/isi

e-ISSN: 2656-4882

\section{Enterprise Architecture Planning (EAP)}

Berikut merupakan gambar 1 lapisan EAP (Spewak, dan Hill 1993) :

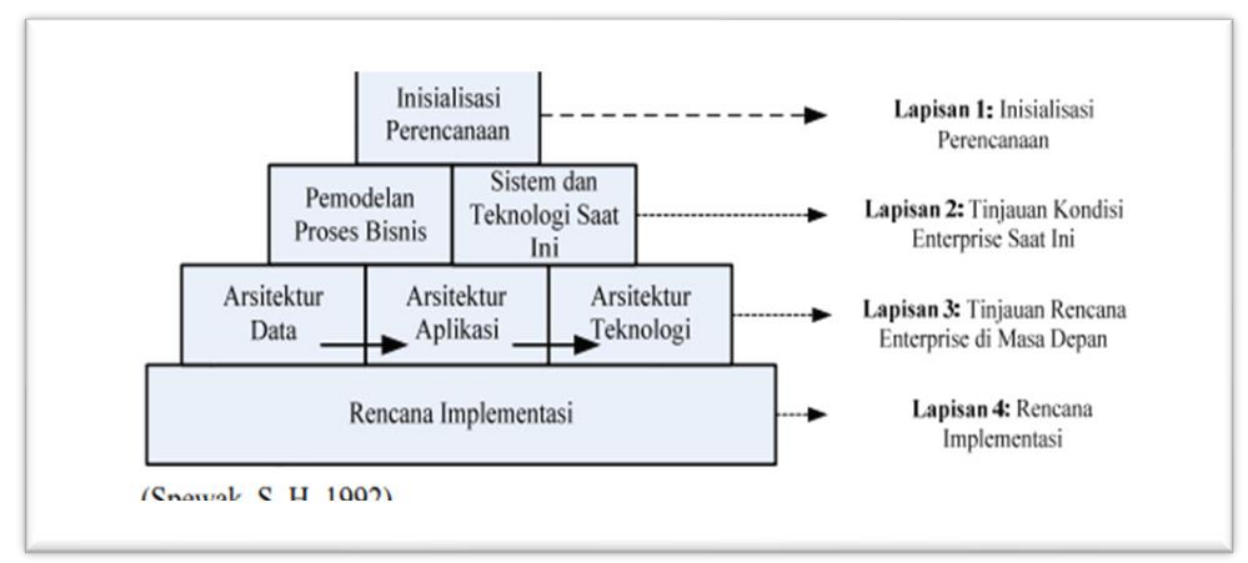

Gambar 1 lapisan EAP (Spewak, dan Hill 1993)

Enterprise Architecture Planning (EAP) merupakan suatu pendekatan yang dibuat oleh Steven H. Spewak untuk membangun arsitektur enterprise dengan berdasarkan dorongan data dan dorongan bisnis. Enterprise Architecture Planning adalah proses pendefinisian arsitektur dalam penggunaan informasi untuk mendukung bisnis dan rencana untuk mengimplementasikan arsitektur tersebut (Spewak, 1992). Jadi Enterprise Architecture Planning (EAP) bukan suatu perancangan tetapi pendefinisian. Sedangkan kata "rencana" secara umum adalah membicarakan tentang definisi arsitektur apa yang dibutuhkan dan rencana dukungan diartikan sebagai kapan arsitektur tersebut akan diimplementasikan (Spewak, 1992) [6].

Lapisan pada EAP terdiri dari empat lapisan sebagai berikut:

\section{Inisialisasi Perencanaan}

Penentuan ruang lingkup enterprise, visi, misi, metodologi perencanaan serta membentuk perencanaan kerja agar Enterprise Architecture Planning (EAP) terarah, selesai tepat waktu dan hasil dari tahapan perencanaan arsitektur Enterprise yaitu rencana kerja yang baik dan komitmen dari suatu organisasi untuk melanjutkan ke tahap berikutnya agar perusahaan yang dikelola menjadi lebih efektif [1].

2. Pemodelan Bisnis dan Sistem Teknologi Saat Ini.

Membangun suatu basis pengetahuan mengenai bisnis dan informasi yang digunakan saat ini. Tahap ini merupakan proses mendefinisikan arsitektur serta rencana implementasi. Mengidentifikasi dan mendokumentasikan sistem aplikasi dan platform teknologi yang digunakan mendukung fungsi bisnis saat. Hasil dokumentasi disebut sebagai Katalog (Information Resource Catalog atau IRC) atau disebut juga Systems Inventory. IRC tidak menjabarkan setiap sistem secara terperinci, melainkan hanya ringkasannya saja[7]. 
Vol. 3, No. 2, June 2021

p-ISSN: 2656-5935 http://journal-isi.org/index.php/isi

e-ISSN: 2656-4882

3. Arsitektur data,Arsitektur Aplikasi, dan Arsitektur Teknologi.

Mengidentifikasi dan mendefinisikan jenis- jenis data utama atau entitas data yang diperlukan. Pemodelan untuk menggambarkan hubungan antar entitas data menggunakan Entity-Relationship Diagram (ERD). Arsitektur Aplikasi bertujuan untuk mengidentifikasi dan mendefinisikan jenis aplikasi utama yang dibutuhkan untuk mengelola data dan mendukung fungsi bisnis. Arsitektur aplikasi bukan rancangan sistem tetapi merupakan pendefinisian aplikasi yang dibutuhkan untuk mengelola data dan menyediakan informasi bagi user untuk melakukan fungsi bisnis. Arsitektur Teknologi mengidentifikasi dan mendefinisikan prinsip teknologi yang dibutuhkan untuk menyediakan lingkungan yang mendukung aplikasi pada arsitektur aplikasi yang disusun sebelumnya dalam mengelola data dan mendukung fungsi bisnis. Arsitektur teknologi merupakan definisi dari teknologi yang akan mendukung fungsi bisnis dengan menyediakan lingkungan sharing data[7].

\section{Rencana Implementasi}

Rencana Implementasi ini bertujuan untuk menyusun dan menyiapkan suatu rekomendasi pengimplementasian dengan menentukan kebijakan, standar, prosedur-prosedur dan yang sudah direncanakan secara terperinci [7] .

\section{PENELITIAN TERDAHULU}

Penelitian terdahulu yang dilakukan oleh penulis masih berhubungan dengan penelitian yang dilakukan yaitu dengan menggunakan Enterprise Architecture Planning. Penelitian terdahulu tersebut membahas mengenai Teknologi Informasi pada sebuah organisasi Teknologi informasi semakin lama semakin maju dan setiap saat selalu ada perkembangannya yang berpengaruh terhadap berbagai aspek kehidupan. Salah satu diantaranya adalah aspek perekonomian yang berdampak positif bagi organisasi. Oleh karena itu, setiap organisasi berusaha untuk menerapkan teknologi informasi dengan tujuan meningkatkan efektifitas dalam proses bisnis, agar organisasi mampu memberikan nilai tambah berupa keunggulan dalam persaingan bisnis. Enterprise Architecture Planning (EAP) merupakan suatu metode pendekatan dalam perencanaan kualitas data yang berorientasi pada kebutuhan bisnis, perencanaan ini terdiri dari arsitektur data, aplikasi dan infrastruktur teknologi. Tujuan penelitian ini untuk menghasilkan proses bisnis organisasi agar berjalan lebih efektif. Hasil dari penelitian ini untuk meningkatkan penyelarasan bisnis dan teknologi informasi pada organisasi [8].

Penelitian terdahulu membahas perencanaan strategis sistem informasi Perencanaan strategi sistem informasi dilakukan untuk mendapatkan solusi terhadap perencanaan sistem informasi di organisasi. Proses perencanaan strategis sistem informasi harus dikelola berdasarkan suatu petunjuk yang jelas dengan tujuan untuk menyelaraskan antara strategis dan tujuan bisnis dan organisasi. Saat ini penerapan sistem informasi di Dinas Pekerjaan Umum Kota Semarang masih 
Vol. 3, No. 2, June 2021

p-ISSN: 2656-5935 http://journal-isi.org/index.php/isi

e-ISSN: 2656-4882

belum optimal dikarenakan Sebagian besar pengelolaan datanya masih bersifat manual, maka dari itu dibutuhkan strategis sistem informasi yang tujuannya adalah proses bisnis dalam organisasi berjalan efektif dan efisien dalam mendukung proses bisnis organisasi. Enterprise Architecture Planning (EAP) merupakan proses pendefinisian arsitektur dalam penggunaan informasi untuk mendukung bisnis dalam rencana untuk mengimplementasikanarsitektur tersebut. Dengan menggunakan Enterprise Architecture Planning (EAP) dapat dijadikan metode untuk mencapai sasaran bisnis bagi Dinas Pekerjaan Umum Kota Semarang, selain itu keuntungan menggunakan Enterprise Architecture Planning (EAP) untuk mendukung pengambilan keputusan dan perencanaan yang baik di organisasi[4] .

Pencapaian tujuan suatu enterprise menghadapi tantangan serta perubahan memerlukan strategi yang penting dan semakin banyak digunakan adalah pemanfaatan dan peningkatan dukungan sistem informasi bagi enterprise. Pembangunan misi pada strategis sistem informasi memerlukan keterpaduan arah dalam perencanaan pelaksanaan dan pengendalian yang selaras dengan strategis sistem informasi. perencanaan ini dapat memanfaatkan metodologi Perencanaan Arsitektur enterprise yang menghasilkan arsitektur data, arsitektur aplikasi,arsitektur teknologi dan arahan implementasi [9] .

Koperasi produksi susu (KPS) Bogor merupakan koperasi pertanian yang berkembang di Kota Bogor. Koperasi ini membutuhkan pengembangan teknologi untuk tata kelola operasional yang lebih baik. Tujuan utama dari pembahasan ini untuk perencanaan pembangunan teknologi informasi dalam bentuk arsitektur enterprise dengan menggunakan Enterprise Architecture Planning (EAP) di Koperasi Produksi Susu Bogor. Hasil dari studi kasus adanya beberapa rekomendasi yang terdiri dari arsitektur data, arsitektur aplikasi dan aplikasi Teknologi. Rekomendasi Arsitektur data berupa data dan entitas data yang digunakan untuk menjelaskan entitas utama proses bisnis. Rekomendasi Arsitektur Aplikasi yaitu merekomendasi aplikasi yang dibangun berdasarkan prioritas pembangunannya. Rekomendasi teknologi yaitu bagian pembangunan network[10].

Perencanaan sistem informasi pada kecamatan sering dijumpai ketidak selarasan dengan proses bisnis dan IT. Untuk dapat menggabungkan informasi dan mensinergikan bisnis dan IT di kecamatan yang ada di kota Samarinda, maka diperlukan suatu perencanaan strategis sistem informasi. Metode yang digunakan untuk menggambarkan kondisi saat ini dan rancangan Enterprise Arsitektur adalah Enterprise Architecture Planning (EAP). Metode ini digunakan untuk menjabarkan atau merancang Enterprise Architecture yang tepat untuk mencapai tujuan bisnis pada kecamatan. [11]. Penelitian kali ini akan lebih berfokus pada rencana dalam penggunaan sistem yang dapat mendukung kinerja pada sinode GKJ pada masa mendatang. Sinode gkj untuk saat ini masih terdapat banyak sistem maupun aplikasi yang ada belum dimanfaatkan secara maksimal, dengan begitu 
Vol. 3, No. 2, June 2021

p-ISSN: 2656-5935 http://journal-isi.org/index.php/isi e-ISSN: 2656-4882

penelitian ini membantu mamberikan arahan dan perencanaan agar penggunaan sistem dapat digunakan secara maksimal.

\section{HASIL DAN PEMBAHASAN}

\section{Langkah-langkah dalam Perencanaan Strategi Sistem Informasi di Sinode GKJ}

\section{A. Pemodelan bisnis.}

Perencanaan strategis sistem informasi menggunakan pemodelan bisnis yang digunakan dalam penelitian ini menggunakan Value Chain untuk mengetahui bagaimana aktivitas yang dijalankan di sinode seperti aktivitas utama dan aktivitas pendukung yang digambarkan dengan menggunakan Value Chain. Analisis Value Chain dilakukan untuk memetakan suatu proses bisnis yang ada pada organisasi dan terdapat dua aktivitas yaitu aktivitas utama dan aktivitas pendukung. Mengacu pada dokumen organisasi yaitu untuk menyatakan tugas dan fungsi setiap unit kerja terhadap masing-masing proses pekerjaan yang terjadi di setiap unit kerja yang terdapat pada organisasi tersebut[12] . Berikut merupakan Gambar 3 Value Chain pemodelan bisnis:
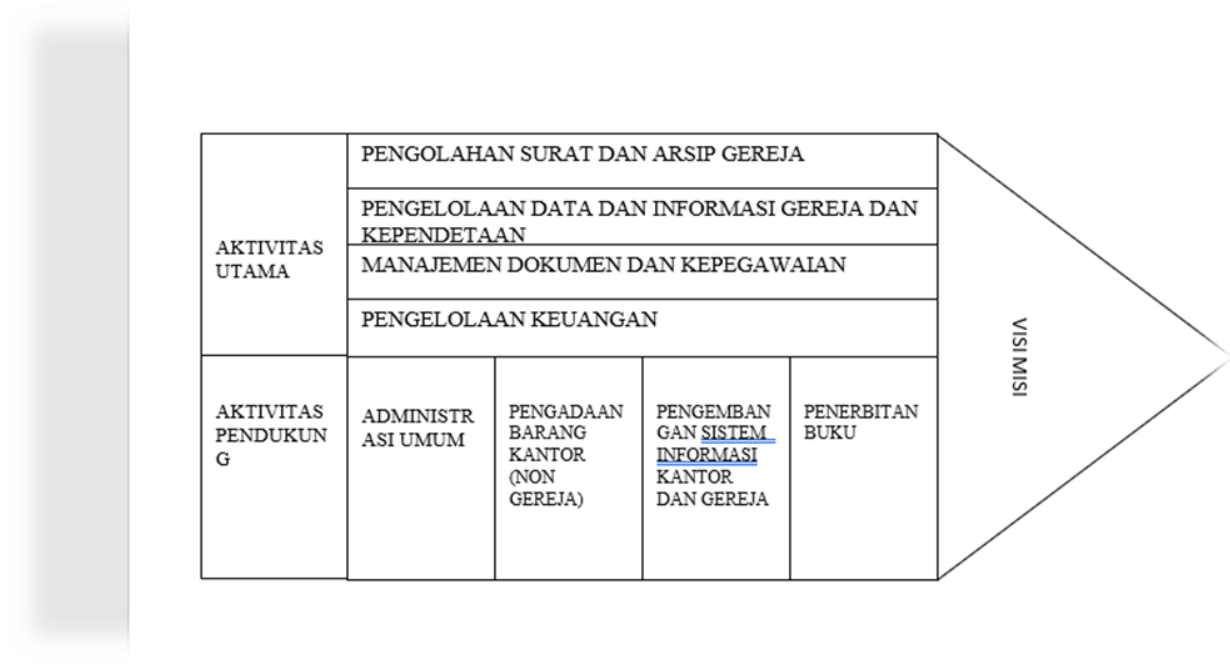

Gambar 3 Value Chain pemodelan bisnis

Berdasarkan aktivitas di sinode GKJ memiliki dua aktivitas yaitu aktivitas utama dan aktivitas pendukung. Dalam aktivitas utama terdapat pengolahan surat dan arsip gereja,pengelolaan data dan informasi gereja dan kependetaan,manajemen 
Vol. 3, No. 2, June 2021

p-ISSN: 2656-5935 http://journal-isi.org/index.php/isi e-ISSN: 2656-4882

dokumen dan kepegawaian, dan pengelolaan keuangan. Adapun aktivitas pendukung terdapat administrasi umum,pengadaan barang kantor (luar kantor), pengembangan sistem informasi kantor dan gereja, dan penerbitan buku.

\section{B. Analisis SWOT}

SWOT merupakan metode perencanaan strategis yang digunakan untuk mengevaluasi kekuatan (strengths), kelemahan (weaknesses), peluang (opportunities), dan ancaman (threats) dalam suatu kinerja yang sedang dalam proses perencanaan atau sedang dalam perencanaan agar organisasi lebih terarah untuk melakukan sebuah pekerjaannya[4] . Berikut merupakan Tabel 1 Analisis SWOT di Sinode GKJ:

Tabel 1 Analisis SWOT di Sinode GKJ

\begin{tabular}{|c|c|}
\hline SWOT & Analisis \\
\hline - Strength & $\begin{array}{ll}\text { - } & \text { Terdapat sistem yang ada untuk menunjang } \\
& \text { pekerjaan. } \\
\text { - } & \text { Reputasi yang baik dalam pelayanan. }\end{array}$ \\
\hline - Weakness & 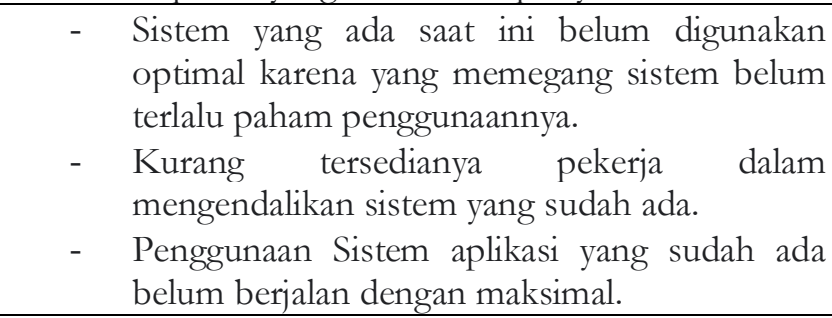 \\
\hline - Opportunity & $\begin{array}{l}\text { - Adanya sarana untuk membantu } \\
\text { mengembangkan suatu sistem yang sudah ada. } \\
\text { - Adanya konsistenisasi dari suatu organisasi } \\
\text { untuk mempercepat pengembangan sistem } \\
\text { yang dibutuhkan. } \\
\text { Dukungan dari anggota klasis, gereja, dan } \\
\text { Lembaga Kerjasama cukup tinggi. }\end{array}$ \\
\hline - Threat & $\begin{array}{l}\text { - Munculnya teknologi baru yang semakin } \\
\text { berkembang. } \\
\text { - Pertumbuhan gereja yang cepat, berpengaruh } \\
\text { terhadap pengambilan keputusan. }\end{array}$ \\
\hline
\end{tabular}

- Strength merupakan analisis yang menjadi ketersediaan untuk sumber daya anggota

- Weakness merupakan analisis yang melihat kekurangan untuk produk seperti sarana dan prasarana yang belum tercukupi.

- Opportunity merupakan analisis yang mempunyai tugas untuk melihat kesempatan untuk melihat apa yang saat ini sedang menjadi tren. 
Vol. 3, No. 2, June 2021

p-ISSN: 2656-5935 http://journal-isi.org/index.php/isi e-ISSN: 2656-4882

- Threat adalah analisis yang hambatan yang akan mengancam perkembangan bisnis yang akan dilaksanakan.

\section{Sistem yang digunakan saat ini.}

Sistem yang digunakan saat ini profil perusahaan,SLIM, IPOST, dan Sistem Surat dan kearsipan surat memiliki permasalahan dibagian SI/TI karena SDM dirasa kurang siap atau belum dapat menggunakan sistem yang ada sehingga penggunaan dalam menjalankan sistem masih belum maksimal.

\section{Arsitektur Data}

Arsitektur data dibuat untuk mendefinisikan entitas data yang sudah dikelompokkan berdasarkan fungsi bisnis agar dapat digunakan untuk mendukung aktivitas bisnis yang sudah ada di Sinode GKJ. Pendefinisian entitas data Dalam pembangunan arsitektur data, Entitas data berupa jenis data utama untuk menunjang fungsi bisnis dapat diartikan pada arsitektur bisnis yang harus diidentifikasi dan didefinisikan sesuai dengan arsitektur data yang ingin dibuat[13].

Arsitektur data merupakan arsitektur pertama yang dibangun dari ketiga arsitektur yang ada karena kualitas data merupakan pondasi utama produk sistem informasi(spewak,2006). Arsitektur data memiliki entitas data yang berguna untuk mendefinisikan kebutuhan perusahaan data yang mendukung suatu proses bisnis, Entitas data memiliki masing-masing atribut dan relasi dengan entitas lainnya[14]. Berikut merupakan Tabel 2 Entitas data:

Tabel 2 Entitas data

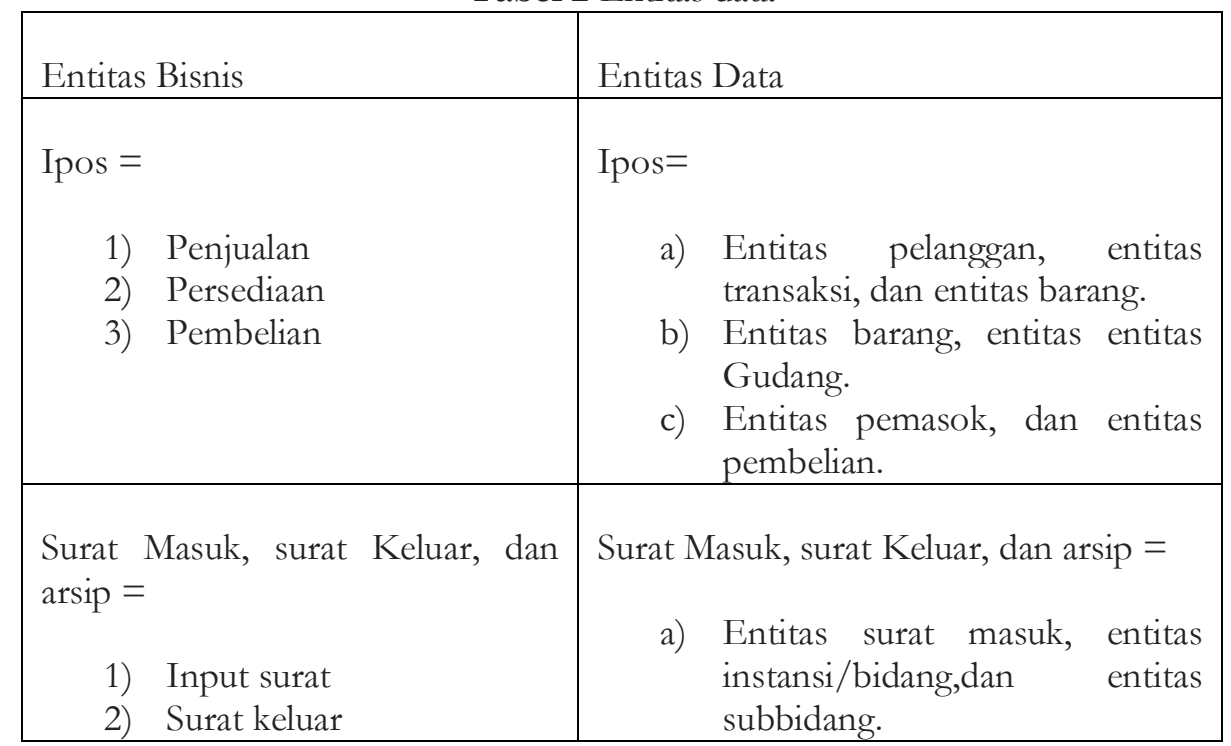


Vol. 3, No. 2, June 2021

p-ISSN: 2656-5935 http://journal-isi.org/index.php/isi e-ISSN: 2656-4882

\begin{tabular}{|c|c|}
\hline $\begin{array}{l}\text { 3) Laporan } \\
\text { 4) Pengarsipan }\end{array}$ & $\begin{array}{l}\text { b) Entitas surat masuk, entitas } \\
\text { instansi/bidang,dan } \\
\text { subbidang. } \\
\text { c) Entitas } \\
\text { entitas surat keluar. } \\
\text { d) Entitas dokumen, entitas box, } \\
\text { entitas Lembaga dan entitas } \\
\text { format. }\end{array}$ \\
\hline SLIM/perpustakaan= & SLIM/perpustakaan= \\
\hline $\begin{array}{l}\text { 1) Penginputan. } \\
\text { 2) Pengadaan. } \\
\text { 3) Pinjaman. }\end{array}$ & $\begin{array}{l}\text { a) Entitas petugas, entitas buku, } \\
\text { dan entitas anggota. } \\
\text { b) Entitas buku. } \\
\text { c) Entitas buku, entitas anggota } \\
\text { dan entitas petugas. }\end{array}$ \\
\hline
\end{tabular}

\section{E. Arsitektur Aplikasi}

Arsitektur Aplikasi dibuat setelah mengolah arsitektur data yang didefinisikan entitasnya agar arsitektur aplikasi dapat berjalan sesuai dengan proses bisnis dan pengelolaan data pada organisasi. Arsitektur Aplikasi dibangun untuk mendefinisikan aplikasi-aplikasi utama yang dibutuhkan oleh enterprise dalam mengolah data dan mendukung fungsi bisnis yang ada diorganisasi. Arsitektur aplikasi adalah suatu perencanaan aplikasi yang akan dikembangkan agar dapat memenuhi kebutuhan organisasi berupa suatu deskripsi kandidat aplikasi yang akan dikembangkan. kandidat aplikasi didapatkan dari hubungan antara entitas data dan proses bisnis yang sudah dijelaskan pada arsitektur data. Kandidat aplikasi merupakan sebuah tujuan mempersingkat agar dapat membantu kebutuhan pada proses bisnis pada organisasi[15]. Berikut merupakan Tabel 3 Usulan Arsitektur Aplikasi:

Tabel 3 Usulan Arsitektur Aplikasi

\begin{tabular}{|l|l|l|l|}
\hline Aktivitas & Kebutuhan & Usulan si/ti & Keterangan \\
\hline $\begin{array}{l}\text { Pelayanan } \\
\text { informasi } \\
\text { profil }\end{array}$ & $\begin{array}{l}\text { Membutuhkan } \\
\text { web profil } \\
\text { untuk } \\
\text { memberikan } \\
\text { informasi dan } \\
\text { layanan kepada } \\
\text { gereja/ umum. }\end{array}$ & $\begin{array}{l}\text { informasi } \\
\text { publik/umum }\end{array}$ & $\begin{array}{l}\text { Memperbaharui sistem } \\
\text { informasi yang sudah ada } \\
\text { diorganisasi agar dapat } \\
\text { memberikan pelayanan } \\
\text { yang detail tentang } \\
\text { informasi profil organisasi } \\
\text { yang sedang dijalankan. }\end{array}$ \\
\hline
\end{tabular}


Vol. 3, No. 2, June 2021

p-ISSN: 2656-5935 http://journal-isi.org/index.php/isi e-ISSN: 2656-4882

\begin{tabular}{|c|c|c|c|}
\hline $\begin{array}{l}\text { Persuratan } \\
\text { dan arsip }\end{array}$ & $\begin{array}{l}\text { Membutuhkan } \\
\text { sistem untuk } \\
\text { mengelola, } \\
\text { menyimpan } \\
\text { arsip dokumen } \\
\text { dan arsip } \\
\text { laporan sinode, } \\
\text { klasis, gereja } \\
\text { dan lembaga. }\end{array}$ & $\begin{array}{l}\text { Sistem } \\
\text { Informasi E- } \\
\text { Document }\end{array}$ & $\begin{array}{l}\text { Memperbaharui sistem } \\
\text { informasi yang sudah ada } \\
\text { agar dapat mempermudah } \\
\text { untuk melihat,mencari, dan } \\
\text { membaca dokumen melalui } \\
\text { E-document karena } \\
\text { merupakan sebuah media } \\
\text { elektronik atau teknologi } \\
\text { elektronik untuk } \\
\text { memudahkan pengguna } \\
\text { mencari dan melihat data } \\
\text { maka di E-document dapat } \\
\text { dikelompokan. }\end{array}$ \\
\hline Perpustakaan & $\begin{array}{l}\text { Membutuhkan } \\
\text { sistem untuk } \\
\text { mengelola, } \\
\text { penyimpan } \\
\text { buku sejarah } \\
\text { dan teologia } \\
\text { guna } \\
\text { membantu } \\
\text { gereja maupun } \\
\text { mahasiswa } \\
\text { dalam } \\
\text { pencarian } \\
\text { sumber data } \\
\text { informasi } \\
\text { sejarah sinode. }\end{array}$ & $\begin{array}{l}\text { Sistem } \\
\text { Informasi } \\
\text { perpustakaan } \\
\text { berbasis web }\end{array}$ & $\begin{array}{l}\text { Membuat sistem baru } \\
\text { berbasis web untuk } \\
\text { mempermudah gereja atau } \\
\text { orang yang ingin } \\
\text { mengetahui sejarah dan } \\
\text { teologi tentang sinode } \\
\text { dapat membuka wab } \\
\text { tersebut. }\end{array}$ \\
\hline Penjualan & $\begin{array}{l}\text { Membutuhkan } \\
\text { sistem } \\
\text { informasi yang } \\
\text { terintegrasi } \\
\text { dengan } \\
\text { wa/telegram, } \\
\text { untuk } \\
\text { memudahkan } \\
\text { tagihan, } \\
\text { informasi } \\
\text { terbitan buku } \\
\text { terbaru dll. } \\
\text { Untuk } \\
\text { meningkatkan } \\
\text { pelayanan }\end{array}$ & $\begin{array}{l}\text { Sistem } \\
\text { Informasi } \\
\text { penjualan } \\
\text { berbasis web }\end{array}$ & $\begin{array}{l}\text { Membuat sistem baru } \\
\text { berupa web khususnya } \\
\text { untuk penjualan agar } \\
\text { memudahkan dan } \\
\text { peningkatan pelayanan } \\
\text { kepada pelanggan dan } \\
\text { sistem informasi yang } \\
\text { digunakan agar pelanggan } \\
\text { juga dapat memesan } \\
\text { dengan mudah. }\end{array}$ \\
\hline
\end{tabular}


Vol. 3, No. 2, June 2021

p-ISSN: 2656-5935 http://journal-isi.org/index.php/isi e-ISSN: 2656-4882

\begin{tabular}{|l|l|l|l|}
\hline & $\begin{array}{l}\text { kepada } \\
\text { pelanggan. }\end{array}$ & & \\
\hline Gudang & $\begin{array}{l}\text { membutuhkan } \\
\text { sistem } \\
\text { informasi yang } \\
\text { untuk } \\
\text { mengelola stok } \\
\text { barang yang ada } \\
\text { di perusahaan }\end{array}$ & $\begin{array}{l}\text { Sistem } \\
\text { Informasi }\end{array}$ & $\begin{array}{l}\text { Mengembangkan sistem } \\
\text { yang sudah ada atau } \\
\text { mengupdate sistem dari } \\
\text { organisasi saat ini. }\end{array}$ \\
& & \\
\hline
\end{tabular}

Tujuan dari arsitektur aplikasi ini adalah untuk mendefinisikan aplikasi gunanya untuk mendukung proses bisnis yang ada di Sinode GKJ. Adapun usulan yg sudah dibuat untuk dikembangkan berdasarkan fungsinya yaitu Sistem informasi publik/umum, Sistem Informasi E-Document, Sistem Informasi perpustakaan berbasis web, Sistem Informasi penjualan berbasis web, dan Sistem Informasi Gudang.

\section{F. Rencana Implementasi}

Implementasi arsitektur enterprise dibuat untuk perkembangan perencanaan sistem informasi yang sebuah berjalan saat ini. Untuk pengembangan dan peningkatan sistem informasi aplikasi sangat dibutuhkan untuk beberapa tahun kedepan sesuai dengan kebutuhan organisasi saat ini. Berikut merupakan tabel 4 Rencana implementasi:

Tabel 4 Rencana Implementasi

\begin{tabular}{|l|l|}
\hline Strategis & Aplikasi Berpotensi Tinggi \\
\hline Pelayanan Informasi Profil & Sistem informasi publik/umum. \\
\hline Persuratan dan Arsip & Sistem Informasi E-Document . \\
\hline Perpustakaan & $\begin{array}{l}\text { Sistem Informasi perpustakaan berbasis } \\
\text { web. }\end{array}$ \\
\hline Penjualan & $\begin{array}{l}\text { Sistem Informasi penjualan berbasis } \\
\text { web. }\end{array}$ \\
\hline Gudang & Sistem Informasi Gudang \\
\hline
\end{tabular}

Urutan dari usulan implementasi sistem informasi untuk pengembangan sistem informasi aplikasi sangat dibutuhkan untuk beberapa tahun kedepan sesuai dengan kebutuhan organisasi saat ini. Berikut merupakan Tabel 5 Urutan Rencana Implementasi: 
Vol. 3, No. 2, June 2021

p-ISSN: 2656-5935 http://journal-isi.org/index.php/isi e-ISSN: 2656-4882

Tabel 5 Urutan Rencana Implementasi

\begin{tabular}{|l|l|l|l|l|l|l|}
\hline \multicolumn{1}{|c|}{ Nama Aplikasi Informasi } & & 2021 & 2023 & 2024 & 2025 & 2026 \\
\hline $\begin{array}{l}\text { Sistem } \\
\text { Perpustakaan. }\end{array}$ & & & & & \\
\hline $\begin{array}{l}\text { Sistem Informasi E- } \\
\text { Document Informasi }\end{array}$ & & & & & & \\
\hline $\begin{array}{l}\text { Sistem berbasis } \\
\text { Penjualan Informasi } \\
\text { Wab. }\end{array}$ & & & & & & \\
\hline $\begin{array}{l}\text { Sistem Informasi E- } \\
\text { Document. Informasi }\end{array}$ & & & & & & \\
\hline $\begin{array}{l}\text { Sistem } \\
\text { Gudang. }\end{array}$ & & & & & & \\
\hline $\begin{array}{l}\text { Sistem } \\
\text { Publik/umum }\end{array}$ & & & & & \\
\hline
\end{tabular}

Tujuan dari Arsitektur Aplikasi untuk mendefinisikan aplikasi untuk mendukung proses bisnis dan mengembangkan sebuah sistem yang sudah ada di Sinode GKJ. Pengembangan aplikasi yang sedang direncanakan dan akan dikembangkan membutuhkan waktu 6 tahun berdasarkan tabel. Urutan perencanaan aplikasi yang dibuat sudah sesuai urutan fungsi dari aplikasi untuk mendukung sistem dan mendukung kegiatan bisnis di Sinode GKJ kedepannya.

Dalam penelitian menggunakan metode Enterprise Architecture Planning (EAP) yang merupakan metode yang dapat merencanakan suatu sistem aplikasi pada perusahaan maupun organisasi tabel diatas menjelaskan perencanaan yang akan diimplementasikan untuk kinerja pada masa mendatang.

\section{KESIMPULAN}

Berdasarkan penelitian yang sudah dilakukan di Sinode GKJ dapat disimpulkan bahwa perencanaan metode Enterprise Architecture Planning (EAP) merupakan perencanaan strategis yang dapat membantu sebuah organisasi sesuai dengan kebutuhan kinerja dan Teknologi yang sudah ada yang sekarang sedang dijalankan. Metode Enterprise Architecture Planning (EAP) dapat mendefinisikan sebuah 
Vol. 3, No. 2, June 2021

p-ISSN: 2656-5935 http://journal-isi.org/index.php/isi

e-ISSN: 2656-4882

perencanaan proses kinerja yang sedang berjalan sampai ke implementasi sistem informasi yang dibuat.

Berdasarkan pembahasan tersebut terdapat aktivitas utama dan aktivitas pendukung di Sinode GKJ. Aktivitas utama yang terdapat di Sinode GKJ terdiri dari pengelolaan surat dan kearsipan gereja, pengelolaan data dan informasi gereja dan kependetaan, manajemen dokumen dan kepegawaian, dan pengelolaan keuangan. Adapun aktivitas pendukungnya terdiri dari administrasi umum, pengadaan barang kantor (luar kantor), pengembangan sistem informasi kantor dan gereja, dan penerbitan buku. Dari menganalisa aktivitas utama dan aktivitas pendukung menghasilkan portofolio aplikasi sistem informasi yang diantaranya terdapat sistem informasi Sistem Informasi Perpustakaan, Sistem Informasi Penjualan berbasis Web, Sistem Informasi E-Document, Sistem Informasi Gudang, dan Sistem Informasi Publik/umum. Hasil perancangan aplikasi sistem informasi yang didapatkan ini bertujuan agar dalam pekerjaan yang dikerjakan semakin efektif dan efisien. Keuntungan menggunakan metode Architecture enterprise planning (EAP) dapat meningkatkan fungsi landasan bisnis untuk mendukung perencanaan dan pengambilan keputusan dengan baik agar dapat mencapai tujuan bisnis kedepannya.

\section{DAFTAR PUSTAKA}

[1] D. Tamala and S. Assegaff, "Perencanaan Strategis Sistem Informasi Menggunakan Metode Enterprise Architecture Planning ( EAP) Pada Kantor Ketahanan Pangan Kabupaten Sarolangun," J. Manaj. Sist. Inf., vol. 5, no. 1, pp. 1-13, 2020.

[2] M. Hidayat, "Penyusunan Rencana Strategis Sistem Informasi STKIP PGRI Banjarmasin Menggunakan Enterprise Architecture Planning," J. Teknol. Rekayasa, vol. 2, no. 2, p. 63, 2018, doi: 10.31544/jtera.v2.i2.2017.63-72.

[3] V. Indra and L. P. Dewi, "Enterprise Architecture Pada CV . Grande Zangrandi Dengan Metode Enterprise Architecture Planning ( EAP)," no. 121, 2018.

[4] S. . Spewak, S. H., Hill, "Enterprise Architecture Planning," Jobn Wiley Sons, Inc., vol. 1, no. 1, 1992.

[5] M. Marini and S. Sarwindah, "Model Arsitektur Enterprise Menggunakan Enterprise Architecture Planning (Eap)," JSiI (Jurnal Sist. Informasi), vol. 6, no. 2, p. 18, 2019, doi: 10.30656/jsii.v6i2.1556. 
[6] novita sari Sasue and agustinus fritz Wijaya, "Perencanaan Strategis Sistem Informasi (Eap ) Framework,” vol. 2, no. 2, pp. 79-87, 2020.

[7] N. S. Sasue and A. F. Wijaya, "Perencanaan Strategis Sistem Informasi Menggunakan Enterprise Architecture Planning (Eap) Framework," J. Bina Komput., vol. 2, no. 2, pp. 79-87, 2020, doi: 10.33557/binakomputer.v2i2.919.

[8] S. Robo, T. Trisno, S. Sunardi, and S. Santosa, "Perencanaan strategis sistem informasi menggunakan Enterprise Architecture Planning pada PT. Karya Cipta Buana Sentosa Maumere," Regist. J. Ilm. Teknol. Sist. Inf., vol. 4, no. 1, p. 41, 2018, doi: 10.26594/register.v4i1.1163.

[9] K. Surendro, B. Kajian, S. Informasi, T. Informatika, and P. Arsitektur, "Pemanfaatan Enterprise Architecture Planning Untuk Perencanaan Strategis Sistem Informasi," Pemanfaat. Enterp. Archit. Plan. Untuk Perenc. Strateg. Sist. Inf., vol. 8, no. 1, pp. 1-9, 2007, doi: 10.9744/informatika.8.1.pp.1-9.

[10] R. Trisminingsih, S. N. Putra, and D. I. Komputer, “1 , 2 1,2,” vol. 9, no. 1, pp. 1138-1148, 2017.

[11] A. Yudhana, R. Umar, and F. Alameka, "Perancangan Sistem Informasi Menggunakan Enterprise Architecture Planning (Studi Kasus Pada Kecamatan di Kota Samarinda)," Khazanah Inform. J. Ilmu Komput. dan Inform., vol. 4, no. 2, p. 114, 2018, doi: 10.23917/khif.v4i2.7039.

[12] Arsul and L. Sularto, "Model Perencanaan Strategis Si/Ti Menggunakan Togaf (the Open Group Architecture Framework) (Studi Kasus : Universitas Pasifik Morotai," J. Tek. Inform., vol. 7, no. 1, pp. 11-20, 2019.

[13] Ramadiani, D. M. Khairina, and A. K. Aziz, "Perancangan E-Government Kelurahan Sempaja Timur Menggunakan Enterprise Architecture Planning," Pros. Semin. Ilmu Komput. dan Teknol. Inf., vol. 2, no. 1, pp. 1-8, 2017.

[14] T. A. S. Musthofa and G. Wang, "Perencanaan Sistem Informasi untuk Mendukung Analisis Pemasaran menggunakan Metode EAP pada PT. Cherokendo Benua Wisata," Eng. Math. Comput. Sci. J., vol. 1, no. 1, pp. 1-9, 2019, doi: 10.21512/emacsjournal.v1i1.5772.

[15] A. W. Nugroho, S. Setiyowati, and A. Kusumaningrum, "Metode Enterprise Architecture Planning Untuk Merencanakan Sistem Informasi Manajemen Anggaran Perguruan Tinggi Swasta," J. Ilm. SINUS, vol. 18, no. 2, p. 43, 2020, doi: $10.30646 /$ sinus.v18i2.477. 